\title{
Genetic connectedness between seven European countries for performance in jumping competitions of warmblood riding horses
}

\author{
C. Ruhlmann ${ }^{\text {a,* }}$, E. Bruns ${ }^{\text {b }}$, E. Fraehr ${ }^{\text {c }}$, J. Philipsson ${ }^{\text {d }}$, S. Janssens ${ }^{\text {e }}$, K. Quinn ${ }^{\text {f }}$, \\ E. Thorén Hellsten ${ }^{\mathrm{d}}$, A. Ricard ${ }^{\mathrm{a}}$ \\ ${ }^{a}$ Station d'Amélioration Génétique des Animaux (SAGA), Institut National de la Recherche Agronomique (INRA), \\ BP 52627, F-31326 Castanet Tolosan, France \\ ${ }^{\mathrm{b}}$ University of Göttingen, Institut Tierzucht und Haustiergenetik, D-37075 Göttingen, Germany \\ ${ }^{\mathrm{c}}$ Danish Agricultural Advisory Centre National Department of Horse Breeding Udkearsvej 15, Skejby DK-8200 Aarhus, Denmark \\ ${ }^{\mathrm{d}}$ Department of Animal Breeding and Genetics, Swedish University of Agricultural Sciences, Box 7023, S-750 07 Uppsala, Sweden \\ ${ }^{\mathrm{e}}$ Katholieke Universiteit Leuven, Kasteelpark Arenberg 30, B-3001 Heverlee, Belgium \\ ${ }^{\mathrm{f}}$ Irish Horse Board, Block B, Maynooth Business Campus, Maynooth, Co. Kildare, Ireland
}

Received 3 December 2007; received in revised form 23 April 2008; accepted 24 April 2008

\begin{abstract}
The aim of this study was to evaluate the genetic connectedness between seven European populations of show jumping horses. Data on stallions bred for jumping and their pedigree up to three generations were provided by seven countries, including 6317 stallions and 22324 different horses. Four different methods were used to estimate the genetic connectedness. Common stallions between countries varied from 0 to 308 and common horses from 130 to 1166. "Genetic similarities" were not the optimal measure of connectedness as number of progeny by country by stallion was not balanced. Correlation between estimates of country effects was computed in a mixed model including the genetic value of horses $\left(h^{2}=0.20\right.$, all relationships included). For Germany, Belgium, France and The Netherlands, these correlations were 0.32 to 0.51 corresponding to a balanced scheme with 11 to 19 progeny per stallion per country. Other correlations ranged from 0.08 to 0.27 . Another method to evaluate the connectedness was (i) to simulate a systematic difference between the true genetic level of countries, (ii) performing a BLUP and (iii) measuring the percentage of the initial difference that could be found between the estimated genetic levels of the corresponding countries. In $50 \%$ of the country pairs, $50 \%$ or more of the initial genetic difference was estimated. It was concluded that the genetic connectedness will allow the estimation of genetic correlations.
\end{abstract}

(c) 2008 Elsevier B.V. All rights reserved.

Keywords: Horse; Show jumping; Genetic connectedness

\footnotetext{
* Corresponding author. Tel.: +33 5612854 53; fax: +33 561285353 . E-mail address: Catherine.Ruhlmann@toulouse.inra.fr (C. Ruhlmann).
}

\section{Introduction}

Official breeding evaluations for the performance of jumping horses have been implemented in several European countries (Koenen and Aldridge, 2002). These estimated breeding values (EBV) are based on national information, whereas the market for breeding 
stallions is international. These same reasons led in the early 1980s the dairy bulls' breeders to ask for more information about the genetic evaluation of bulls in the different countries (Philipsson, 1987). To help the breeders in this way, Interbull was founded first as a joint venture in 1983 then as a permanent subcommittee of the International Committee for Animal Recording (ICAR) in 1988. With the growing exchanges at the international level in the horse industry and the example of the dairy cattle, Interstallion was founded as a working group of the European Association for Animal Production (EAAP), supported by the World Breeding Federation for Sport Horses (WBFSH) and ICAR in 1998. The main objectives of Interstallion (Koenen and Aldridge, 2002) are (1) to describe and discuss current breeding objectives, testing schemes and genetic evaluation procedures, and (2) to explore ways of harmonising and comparing EBVs across countries. In order to compare EBV across countries two pilot projects have been initiated by the Interstallion group (Bruns et al., 2004). In the first project Thorén et al. (in press) analysed EBV in young horse test results (judgments related to riding, dressage and jumping ability) from five studbooks in four countries. In this study, in which we report the results of the second pilot project, we analysed EBV in jumping competition results rather than on indirect criteria. Moreover, three additional countries, without results on young horse tests, have joint the project.

An adequate across-country comparison is only feasible if the populations are well-connected because too weak ties between the countries will lead to large fluctuations in the results (Jorjani et al., 2005, Mark et al., 2005b). Koenen et al. (2004) indicated that European breeding organisations have actively used breeding stallions from other breeding organisations. To evaluate the feasibility of an international comparison of EBV, more detailed and quantitative information on the genetic connectedness between countries is essential. Sufficient connectedness is necessary to allow the estimation of the genetic correlations between the same traits evaluated in different countries (Arnason and Ricard, 2001).

Hence, the aim of this study is the estimation of connectedness between the participating countries concerning breeding evaluation in jumping competition. Each country had chosen for national genetic evaluation criteria and a model following rules based on their existing testing system. So in order to get confidence from breeding organisations, connectedness has been measured from information about sire EBV only even if an animal model is used in national evaluations in each country. Moreover, in most countries, only sire EBVs are published. The connectedness was calculated from data used in the calculation of official sires EBV published by Belgium, Denmark, France, Germany, Ireland, The Netherlands and Sweden. For this connectedness study, no EBV was needed but only amount of information used to calculate EBV for stallions in each country.

\section{Materials}

\subsection{Data}

All the data used for the study were amount of information used to calculate the latest EBV officially published for sires in each following country: Belgium, Denmark, France, Germany, Ireland, The Netherlands and Sweden. There was only one EBV by stallion in each country whatever the breed of the stallion because in each country, all breeds of riding horses are put together to perform one national breeding evaluation for jumping per year. These seven countries represented the collaboration of 22 breeding organisations (Table 1).

Table 1

List of all the participating breeding organisations by countries

\begin{tabular}{ll}
\hline Country & Breeding organisations \\
\hline Belgium & The Royal Belgian Sport Horse Society (sBs) \\
The Belgian Warmblood studbook (BWP) \\
France & Dansk Varmblod (DWB) \\
l'Association Nationale du Selle Francais (SF) \\
l'Association Nationale Anglo-Arabe (AA) \\
Verband hannoverscher Warmblutzüchter (HAN) \\
Verband der Züchter des \\
Holsteiner Pferdes (HOLST) \\
Verband der Züchter u. Freunde \\
des Ostpreußischen \\
Warmblutpferdes Trakehner \\
Abstammung (TRAK) \\
Verband der Züchter des \\
Oldenburger Pferdes (OL) \\
Springpferdezuchtverband \\
Oldenburg-International (OS) \\
Westfälisches Pferdestammbuch (WESTF) \\
Rheinisches Pferdestammbuch (RHEIN) \\
Verband Hessischer Pferdezüchter (HESS) \\
Pferdezuchtverband Rheinland \\
Pfalz Saar (ZWEIB) \\
Pferdezuchtverband Baden-Württemberg \\
(BAD-WÜ) \\
Verband der Pferdezüchter \\
Mecklenburg-Vorpommern (MECKL) \\
Landespferdezuchtverband \\
Berlin-Brandenburg (BRAND) \\
Pferdezuchtverband Sachsen Anhalt (SA) \\
Verband der Thüringer Pferdezüchter (THÜ) \\
The Irish Sport Horse (ISH) \\
Avelsföreningen för svenska varmblodiga \\
hästen (SWB) \\
Koninklijk Warmbloed Paarden stamboek \\
Nederland (KWPN) \\
\\
\end{tabular}


Two files per countries were provided:

(1) A stallion file including all stallions in reproductive activity during the period 2000-2004. For these stallions the following information were provided: ID, name, accuracy of last national EBV (2004), number of own performances in show jumping, number of progeny with performances in show jumping, breed and year of birth.

(2) A pedigree file for the stallions included in the first file, that mean ID and name for ancestors up to three generations if possible.

The number of stallion in each file varied from 67 (Sweden) to 2025 (The Netherlands), with four countries having around 1000 stallions in the stallion file (Table 2). Stallions may have EBV in different countries if they were parents or ancestors of progeny born in different countries. According to the rules of the stud book, the breed of a horse depended on his registration to a breeding organisation at birth. Mainly this breed is a breed of the country of birth (for example, German stud book as Hanoverian or Holstein for horses born in Germany). So that, we put together all different breeds in a country as the native country-breed and breed is confounded with country of birth. Afterwards, when the horse became stallion, he might reproduce in different stud books and then countries. So a stallion will be considered as native if his breed and EBV depended on the same country or foreign if his breed refers to a different country as the one where EBV was calculated. When breed was not provided, this information was extracted from the ID format with the agreement of national researchers.

Stallions from the stallion file differed with respect to the range of birth years, accuracy of EBV and ancestors information supplied, because national rules for genetic evaluation and publication of EBV are not exactly the same from one country to another.

Germany and Sweden have provided information only on old stallions (born between 1971 and 1991); France has provided a list of reproducing stallions, born between 1982 and 1999 and Belgium has provided all stallions approved in a Belgian stud book born between 1970 and 2000. Stallions of the other countries were from intermediate periods (Fig. 1).

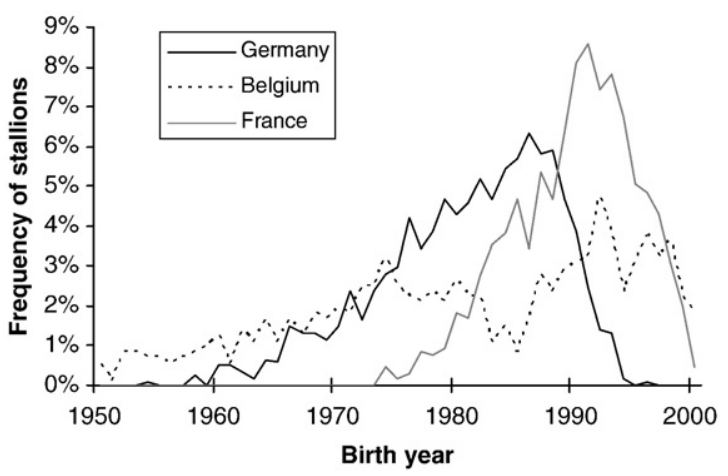

Fig. 1. Distribution of birth year of stallions provided by Germany, Belgium and France.

In relation to accuracy of national EBV, Germany provided only progeny tested stallions with accuracy above 0.75 (mean 0.84 , Table 2). The average accuracy of stallions form France is 0.81 , corresponding to EBVs based on own performances. For Ireland and The Netherlands, average accuracy was lower because their data also included young stallions with a low number of tested progeny (mean accuracy of 0.46 and 0.55 respectively). In Denmark and Sweden, accuracy was not yet calculated, as genetic evaluations on jumping results were not yet published. The average number of progenies was 13 in Denmark and 75 in Sweden.

Belgium, France and Sweden provided complete pedigrees up to three generations. Information from Denmark was complete up to two generations. The Netherlands and Germany provided $100 \%$ of parents but only about $50 \%$ of ancestors in the third generation. Ireland provided pedigrees with $80 \%$ of the parents and $67 \%$ of the grandparents known.

\subsection{Data editing}

The first task was to identify identical horses (stallions and mares) among all files as the same horse could have different ID numbers in different countries. A first automatic check was based on a part of the name (without number, affix or suffix).

Table 2

Overview of data files provided by each country

\begin{tabular}{|c|c|c|c|c|c|c|c|}
\hline \multirow[t]{2}{*}{ Country } & \multirow[t]{2}{*}{ No. of stallions } & \multirow{2}{*}{$\begin{array}{l}\text { No. of progenies } \\
\text { Mean }\end{array}$} & \multirow{2}{*}{$\begin{array}{l}\text { Accuracy of EBV } \\
\text { Mean }\end{array}$} & \multicolumn{2}{|c|}{ Year of birth } & \multicolumn{2}{|c|}{$\begin{array}{l}\% \text { of known ancestors } \\
\text { at different generation }\end{array}$} \\
\hline & & & & Min & Max & 1 gen. $^{2}$ & 2 gen. $^{2}$ \\
\hline Germany (14 org. $\left.{ }^{1}\right)$ & 1232 & 72 & 0.84 & 1954 & 1996 & 99.5 & 82.2 \\
\hline Belgium (sBs, BWP) & 874 & 16 & 0.62 & 1948 & 2000 & 99.4 & 98.0 \\
\hline Denmark (DWB) & 587 & 13 & - & 1953 & 1995 & 99.8 & 99.6 \\
\hline France (SF, AA) & 1179 & 51 & 0.81 & 1972 & 2000 & 100 & 99.9 \\
\hline Netherlands (KWPN) & 2025 & 17 & 0.55 & 1949 & 1997 & 99.6 & 66.3 \\
\hline Ireland (ISH) & 1270 & 8 & 0.46 & 1954 & 1998 & 79.8 & 66.6 \\
\hline Sweden (SWB) & 67 & 75 & - & 1971 & 1992 & 100 & 100 \\
\hline
\end{tabular}

For the abbreviations of the names of the breeding organisations in brackets after the name of the country see Table 1. org. ${ }^{1}$ : breeding organisations, gen. ${ }^{2}$ : generation. 
Then all horses were checked manually to decide which ID numbers belonged to the same horse in the different countries. Decisions were based on second ID number (if provided), name of parents, breed and birth year. The same procedure was carried out for horses with the same ID number but this situation did not occur frequently. A second check was based on the information generated in the first check. If a horse was identified as the same in different countries, all ancestors' ID numbers and all progeny's ID numbers could be matched. An iterative program was written to perform this task.

In the following paragraphs, "stallions" will refer to stallions included in the stallion file provided by each country whereas "horses" will refer to all horses present in the final file, including all the data, i.e. stallions and their ancestors.

After editing the data included 22324 different horses and 6317 stallions.

\section{Measures of connectedness}

In this study four measures of connectedness (MC) were used.

\subsection{MC1 - number of common stallions}

The first measure of connectedness was the number of stallions and ancestors included in two or more national genetic evaluations for jumping, as used, for example by Weigel et al. (2000) for the dairy cattle (common bulls).

\subsection{MC2 - genetic similarity}

Based on the number of common stallions and number of tested progeny, the genetic similarity (GS) between countries was calculated, according to Rekaya et al. (2003). Compared to the number of common stallions between countries, GS is a relative measure (expressed in \%) that takes into account the number of tested progenies in each country. GS is calculated as the proportion of tested progenies by stallions having progenies in two countries, relative to the total number of tested progenies in both countries:

$$
\mathrm{GS}_{i j}=\frac{\sum_{k=1}^{N_{i j}}\left(n_{i k}+n_{j k}\right)}{\sum_{k=1}^{N_{i}} n_{i k}+\sum_{k=1}^{N_{j}} n_{j k}}
$$

with $N_{i j}$ number of stallions with progenies in countries $i$ and $j, N_{i}$ and $N_{j}$ the number of stallions in the country $i$ and $j, n_{i k}$ and $n_{j k}$ the number of progenies of stallion $k$ in country $i$ and $j$, respectively.

As the relative distribution of progenies for each sire in each country varied, the contribution of each country to the GS was calculated by the following formula, as the number of tested progenies in one country sired by a common stallion related to the total number of progenies sired by common stallions into the two countries.

contribution country $i=\frac{\sum_{k=1}^{N_{i j}} n_{i k}}{\sum_{k=1}^{N_{i j}}\left(n_{i k}+n_{j k}\right)}$

\subsection{MC3 - correlation between estimates of country effects}

Thirdly, connectedness was quantified from the correlation between estimates of country effects. We used these variances-covariances because they correlate to the variances-covariances of residuals of estimates of the genetic values (Kennedy and Trus, 1993). These correlations were calculated from the number of own performances of stallions and the number of tested progeny in each country. Even if the information that is available for the study is only about stallion, we started calculation with a animal model to calculate correctly the weighting caused by the number of own performances and by the number of tested progenies. The assumed underlying model was: $y=X b+Z u+e$, with $y$ the vector of performances realised by all horses in all countries, $b$ the vector of fixed effects of countries, $u$ the vector of additive genetic values of all horses and $\mathrm{e}$ the vector of residual. In this model we assumed that the same trait was measured in all countries and that the difference between performances only originates from differences of level between countries. The assumption of the same trait measured in all country lead to genetic correlation fixed to 1 between countries, but in a following study, these correlations will be estimated. To avoid the disparity of the measure of performance in each country, we assumed that each horse had only one performance, considered as a synthesis of the career of the horse. The population was divided in two categories: (1) stallions and ancestors, included in the data files provided, (2) progeny without own progeny, corresponding to the number of progeny given per stallions in the data file. The equations became:

$\left[\begin{array}{l}y_{1} \\ y_{2}\end{array}\right]=\left[\begin{array}{l}X_{1} \\ X_{2}\end{array}\right] b+\left[\begin{array}{cc}Z_{1} & 0 \\ 0 & Z_{2}\end{array}\right]\left[\begin{array}{l}u_{1} \\ u_{2}\end{array}\right]+\left[\begin{array}{l}e_{1} \\ e_{2}\end{array}\right]$

with $y_{1}$ the vector of all the performance of the stallions and ancestors and $y_{2}$ the same vector for the horses without progenies. 
The variance-covariance matrix of standard errors of the parameters was the inverse of the following matrix that did no longer need the information on performances $y$ :

$$
\left[\begin{array}{ccc}
X_{1}^{\prime} X_{1}+X_{2}^{\prime} X_{2} & X_{1}^{\prime} Z_{1} & X_{2}^{\prime} Z_{2} \\
Z_{1}^{\prime} X_{1} & Z_{1}^{\prime} Z_{1}+\alpha A_{11}^{-1} & \alpha A_{12}^{-1} \\
Z_{2}^{\prime} X_{2} & \alpha A_{21}^{-1} & Z_{2}^{\prime} Z_{2}+\alpha A_{22}^{-1}
\end{array}\right]
$$

with $A$ the relationship matrix partitioned according to (1) and (2), and $\alpha=\frac{\sigma_{e}^{2}}{\sigma^{2}}=\frac{1-h^{2}}{h^{2}}$. Heritability $\left(h^{2}\right)$ was assumed to be 0.20 for the trait "career in show jumping" (Thoren Hellsten et al., 2006).

The matrices corresponding to progeny (2) were absorbed and we assumed no relationships between mares of progeny (as in a sire model). The final matrix was:

$$
\left[\begin{array}{cc}
F & C \\
C^{\prime} & D+\alpha A_{11}^{-1}
\end{array}\right]
$$

with

$$
\begin{aligned}
f_{i i} & =\frac{4 \alpha}{3+4 \alpha} \sum_{k=1}^{N} n_{i k}+\sum_{k=1}^{N} m_{i k}, f_{i j}=0 \text { for } i \neq j \\
c_{i j} & =\frac{2 \alpha}{3+4 \alpha} n_{i j}+m_{i j} \\
d_{j j} & =\frac{\alpha}{3+4 \alpha} \sum_{i=1}^{M} n_{i j}+\sum_{i=1}^{M} m_{i j}
\end{aligned}
$$

with $n_{i j}$ the number of tested progenies of the stallion $j$ in the country $i, m_{i j}$ the number of own performance of stallion $j$ in country $i$ ( 0 or 1$). N$ is the total number of stallions with tested progenies, $M$ is the number of countries. All stallions were used in this measure of connectedness, stallions with own performance and stallions with progenies having performances.

This final matrix was directly computed from a data file composed for each stallion by the number of own performance in each country ( 0 or 1$)$, the number of tested progenies in each country and the pedigree file. Only stallions may have performances in different countries (without correlated residuals) which is an approximation due to the unknown proportion of progeny with jumping career in several countries but supposed low (exportation of sport horses is often before performances or after only for international rare horses).

The variance-covariance matrix of estimates of country effects was:

$$
\left[F-C\left(D+\alpha A_{11}^{-1}\right)^{-1} C^{\prime}\right]^{-1} \sigma_{e}^{2}
$$

from which correlations were computed.
3.4. MC4 - estimates of simulated differences between genetic levels in different countries

A fourth measure of the connectedness using the method of Fouilloux et al. (2006) was computed. The principle of the method is to simulate difference between genetic level of the countries at birth of stallions, then to perform a BLUP with a sire model from performances of progeny of these stallions in different countries and finally to measure the percentage of initial difference which could be measured by differences between BLUP evaluation of sires. For this measurement, only stallions with progenies with performances were taken into account.

Consider a country $k$ as the referent country (Ref.) and all other countries considered as pretenders (Pret.). The simulated genetic values of sires born in $k$ were set to 200 . The simulated genetic values of sires born in all other countries were set to 400 . Mean simulated genetic level of any country $j$ was:

$\bar{u}_{j}=0.5\left(200 n_{k j}+400 n_{l \neq k, j}\right) / n_{\cdot j}$

with $n_{k j}$ the number of progeny with performances in country $j$ issued form sires born in the reference country $k$, $n_{l \neq k, j}$ the number of progeny with performances in country $j$ issued from sires born in all the pretenders countries, $n_{\cdot j}$ the total number of progeny with performances in the country $j$.

A BLUP was computed with a single trait sire model, with the relationship matrix including the 22324 horses, and heritability of the trait equal to 0.20 . Progenies from sires born in the referent country were attributed a performance of 100, progenies issued from sires born in the pretenders countries were attributed a performance of 200 . The model included a country effect according to the country were the progeny realised his performances.

The solutions gave the estimated genetic level of each country with:

$\tilde{u}_{j}=0.5 \frac{1}{n_{\cdot j}} \sum_{i=1}^{N_{j}} m_{i j} \hat{u}_{i}$

with $\hat{u}_{i}$ the solution for the sire $i, m_{i j}$ the number of progeny of the sire $i$ with performances in the country $j, n \cdot j$, the total number of progeny with performances in the country $j, N_{j}$ the number of sires with progeny in country $j$.

So that 3 indicators were given for each pairs of countries:

The genetic level of the country (GL): $\bar{u}_{j}$

The differences between simulated genetic levels (D): $\bar{u}_{j}-\bar{u}_{k}$ 
Table 3

Number of common stallions and pedigree horses in national genetic evaluations for show jumping in seven European countries

\begin{tabular}{|c|c|c|c|c|c|c|c|}
\hline & Germany & Belgium & Denmark & France & Netherlands & Ireland & Sweden \\
\hline G & $\begin{array}{l}4274 \\
1232\end{array}$ & 811 & 1017 & 518 & 997 & 286 & 177 \\
\hline B & 23 & $\begin{array}{l}5622 \\
874\end{array}$ & 886 & 1166 & 992 & 456 & 184 \\
\hline D & 129 & 8 & $\begin{array}{l}3497 \\
587\end{array}$ & 613 & 757 & 400 & 296 \\
\hline $\mathrm{F}$ & 48 & 41 & 44 & $\begin{array}{l}5591 \\
1179\end{array}$ & 706 & 457 & 157 \\
\hline NL & 308 & 130 & 114 & 102 & $\begin{array}{l}4843 \\
2025\end{array}$ & 394 & 180 \\
\hline I & 67 & 24 & 44 & 60 & 108 & $\begin{array}{l}4545 \\
1270\end{array}$ & 130 \\
\hline S & 6 & 0 & 14 & 2 & 13 & 8 & $\begin{array}{l}685 \\
67\end{array}$ \\
\hline
\end{tabular}

Germany (G), Belgium (B), Denmark (D), France (F), The Netherlands (NL), Ireland (I) and Sweden (S).

On the diagonal: number of pedigree horses (above) and of stallions (below) per country — above the diagonal: number of common pedigree horses — below the diagonal: number of common stallions.

The ratio between the two differences (simulated difference and estimated difference after the BLUP evaluation): $\left(\tilde{u}_{j}-\tilde{u}_{k}\right) /\left(\bar{u}_{j}-\bar{u}_{k}\right)$ as a percentage.

The procedure has to be run for each pretender country because the place reference/pretender is not symmetric in a couple of countries.

\section{Results}

In the following tables various measures of connectedness were presented. Table 3 reported MC1, Table 4, MC2, Table 5, MC3 and MC4 results were in Table 6.

For MC1 (Table 3) the lowest number of common pedigree horses was between Sweden and Ireland (130) and the highest was between Belgium and France (1166). The number of common stallions in a couple of countries ranged from zero (Sweden-Belgium) to 308 (Germany-The Netherlands). And in five pairs of countries this number was higher than 100: Germany-
Denmark (129), Germany-Netherlands (308), Belgium-Netherlands (130), Denmark-Netherlands (114) and France-Netherlands (102).

For MC2 (Table 4) GS ranged from 0\% (BelgiumSweden) to $32 \%$ (Germany-The Netherlands). The contributions of countries ranged from $0 \%$ (contribution of Belgium to the GS between Belgium and Sweden) and $99 \%$ (contribution of Germany to the GS between Germany and Ireland).

The values of correlations in the MC3 (Table 5) ranged between 0.05 between Ireland and Sweden to 0.51 between Germany and Netherlands. Between seven pairs of countries theses correlations were above 0.30 : Germany-Belgium (0.40), Germany-Denmark (0.40), Germany-France (0.32), Germany-Netherlands (0.51), Belgium-France (0.39), Belgium-Netherlands (0.38), France-Netherlands (0.35).

Table 6 presented the results of MC4, the simulation measure for the seven participating countries. One after another, each country was considered as referent.

Table 4

Genetic similarities between the seven countries for jumping competition (in \%, above diagonal) and the contribution to GS by country in column (in $\%$, below diagonal)

\begin{tabular}{|c|c|c|c|c|c|c|c|}
\hline & Germany & Belgium & Denmark & France & Netherlands & Ireland & Sweden \\
\hline G & 100 & 3 & 20 & 7 & 32 & 12 & 1 \\
\hline B & 63 & 100 & 5 & 5 & 18 & 11 & 0 \\
\hline D & 94 & 93 & 100 & 8 & 13 & 3 & 16 \\
\hline $\mathrm{F}$ & 84 & 69 & 13 & 100 & 18 & 17 & 1 \\
\hline NL & 80 & 80 & 19 & 56 & 100 & 19 & 2 \\
\hline I & 99 & 98 & 83 & 95 & 94 & 100 & 5 \\
\hline$S$ & 48 & 0 & 17 & 2 & 43 & 2 & 100 \\
\hline
\end{tabular}

Germany (G), Belgium (B), Denmark (D), France (F), The Netherlands (NL), Ireland (I) and Sweden (S). 
Table 5

Correlations between estimates of country effects

\begin{tabular}{|c|c|c|c|c|c|c|c|}
\hline & Germany & Belgium & Denmark & France & Netherlands & Ireland & Sweden \\
\hline G & & 0.40 & 0.40 & 0.32 & 0.51 & 0.13 & 0.21 \\
\hline B & & & 0.21 & 0.39 & 0.38 & 0.11 & 0.12 \\
\hline D & & & & 0.18 & 0.27 & 0.08 & 0.14 \\
\hline $\mathrm{F}$ & & & & & 0.35 & 0.12 & 0.10 \\
\hline NL & & & & & & 0.13 & 0.17 \\
\hline I & & & & & & & 0.05 \\
\hline $\mathrm{S}$ & & & & & & & \\
\hline
\end{tabular}

Germany (G), Belgium (B), Denmark (D), France (F), The Netherlands (NL), Ireland (I) and Sweden (S).

Results were given horizontally (i.e., on the first line Germany was referent).

With the initial values chosen for the simulation, a genetic level (GL) on the diagonal, of 100 corresponded to a closed country with no importation of stallion or semen (for example Germany and France). At the opposite a GL close to 200 inform that this country use a lot of foreign stallion in the breeding for sport horse (for example Denmark). For the off diagonal elements, a GL close to 100 refers to a situation where the country considered as pretender used mostly stallion native from the referent country (for example 163.4 Germany(Ref.) and Sweden(Pret.)). And an off diagonal GL close to 200 meant that the pretender used almost no stallion from the referent (for example 200 Sweden(Ref.) and Germany(Pret.) or 200 Ireland(Ref.) and Germany (Pret.)). In our study the lowest GL was for France (103.4) and the highest was 200 and was the case for several pairs: for example, between Belgium(Ref.) and Sweden(Pret.), Belgium(Ref.) or Denmark(Ref.) and Germany(Pret.), or Ireland(Ref.) and Belgium(Pret.).

The difference of simulated genetic levels $(D)$ provided information on the total exchanges of stallions between countries. It can vary from 100 (the two

Table 6

Difference of estimated/simulated genetic levels between countries from the simulation

\begin{tabular}{|c|c|c|c|c|c|c|c|c|}
\hline \multicolumn{9}{|c|}{ Pretenders } \\
\hline Ref. $^{1}$ & & Germany & Belgium & Denmark & France & Netherlands & Ireland & Sweden \\
\hline \multirow[t]{3}{*}{ G } & GL & 110.5 & 173.0 & 149.7 & 198.1 & 180.0 & 193.1 & 163.4 \\
\hline & $\mathrm{D}$ & & 62.4 & 39.1 & 87.5 & 69.5 & 82.5 & 52.9 \\
\hline & $\%$ & & 55.5 & 51.4 & 63.9 & 55.9 & 46.5 & 61.9 \\
\hline \multirow[t]{3}{*}{ B } & GL & 199.9 & 165.8 & 199.9 & 199.6 & 199.7 & 199.5 & 200.0 \\
\hline & $\mathrm{D}$ & 34.1 & & 34.1 & 33.8 & 33.9 & 33.7 & 34.2 \\
\hline & $\%$ & 29.1 & & 27.6 & 31.6 & 31.0 & 24.9 & 27.6 \\
\hline \multirow[t]{3}{*}{$\mathrm{D}$} & GL & 200.0 & 200.0 & 165.6 & 200.0 & 199.8 & 199.8 & 198.6 \\
\hline & $\mathrm{D}$ & 34.4 & 34.4 & & 34.4 & 34.2 & 34.2 & 33.0 \\
\hline & $\%$ & 35.3 & 33.6 & & 33.9 & 33.7 & 32.8 & 37.5 \\
\hline \multirow[t]{3}{*}{$\mathrm{F}$} & GL & 197.7 & 173.8 & 199.1 & 103.4 & 196.2 & 197.7 & 199.3 \\
\hline & $\mathrm{D}$ & 94.2 & 70.4 & 95.7 & & 92.8 & 94.3 & 95.9 \\
\hline & $\%$ & 57.8 & 51.8 & 56.1 & & 57.8 & 54.1 & 54.3 \\
\hline \multirow[t]{3}{*}{ NL } & GL & 198.7 & 189.8 & 198.9 & 199.2 & 132.4 & 198.5 & 192.1 \\
\hline & $\mathrm{D}$ & 66.2 & 57.4 & 66.5 & 66.7 & & 66.1 & 59.6 \\
\hline & $\%$ & 55.2 & 55.8 & 52.1 & 55.5 & & 46.1 & 52.3 \\
\hline \multirow[t]{3}{*}{ I } & GL & 200.0 & 200.0 & 199.5 & 199.9 & 200.0 & 151.8 & 200.0 \\
\hline & $\mathrm{D}$ & 48.2 & 48.2 & 47.8 & 48.2 & 48.2 & & 48.2 \\
\hline & $\%$ & 43.9 & 45.1 & 44.4 & 45.3 & 44.7 & & 44.1 \\
\hline \multirow[t]{3}{*}{ S } & GL & 200.0 & 200.0 & 198.3 & 200.0 & 200.0 & 199.9 & 150.5 \\
\hline & $\mathrm{D}$ & 49.5 & 49.5 & 47.8 & 49.5 & 49.5 & 49.5 & \\
\hline & $\%$ & 51.4 & 50.6 & 52.4 & 50.3 & 50.7 & 48.5 & \\
\hline
\end{tabular}

Ref. $^{1}$ : country considered as referent one after the other. Germany (G), Belgium (B), Denmark (D), France (F), The Netherlands (NL), Ireland (I) and Sweden (S).

GL: simulated genetic level from simulation.

D: difference of simulated genetic levels between the 2 countries.

$\%$ : percentage of simulated difference estimated after an evaluation by a BLUP model. 
countries are closed to each other) to -100 (in the two countries, pretender and referent, all sires are native from the other). In the current study, the $D$ varied from 33.0 between Denmark(Ref.) and Sweden(Pret.) to 95.9 between France(Ref.) and Sweden(Pret.).

The criterion that measured the connectedness between two countries (Table 6) was the rate of the initial difference re-estimated. This percentage grew in the same way as the connectedness, and should be read horizontally, giving which proportion of the difference of genetic level between the referent and each pretender was estimated. This rate ranged between $24.9 \%$ for Belgium as referent and Ireland as pretender and 63.9\% for Germany as referent and France as pretender.

\section{Discussion}

\subsection{Is the data consistent to measure connectedness?}

We encountered huge problems with the identification of older horses. At present, the Unique Equine Life Number (UELN) is not available for horses born before the UELN introduction in 2000. Problems arise because new numbers have been assigned by breeding organisations to imported horses without saving the original ID numbers. This created a huge problem in identification, mainly because ID numbers are not the same but also because the name is not exactly identical either. This makes automatic checking unfeasible. This problem underlines the importance of the use of unique ID numbers for all horses, the UELN, and the updating of UELN for older horses.

Data provided by the different countries were not completely comparable, probably because requirements depended on present EBV calculated in each country. "Stallions with EBV" was interpreted either as progeny tested stallions (Germany), stallions in reproductive activity (France), or all stallions ever approved by a breeding organisation since beginning of evaluation (Belgium). These differences may lead to an underestimation of the connectedness with all measurements because we compared populations that were slightly different. Especially for Sweden, connectedness might have been underestimated due to the low number of stallions provided. For Germany, connectedness with France, Belgium and The Netherlands should also have been higher if younger stallions had been included, thus reflecting the recent increase in commercial exchanges. Nevertheless, we didn't identify horses with multiple jumping careers in different countries and they were double counted which may overestimate genetic correlation. But maybe this overestimation is less important than the underestimation cited before, because these horses with multiple jumping career represented a low percentage of the population.

\subsection{Genetic similarities were inadequate to measure connectedness}

Four measurements of connectedness were used in this study. $\mathrm{MC1}$ is a rough criterion but easy to understand for breeders and the starting point of the others. MC2 (genetic similarities) was used in order to take into account the size of the stallion populations in each country and to compare our results to results obtained in dairy cattle (Jorjani, 2000; Weigel et al., 2000) and especially in horses (Thorén et al., in press).

The measure of connectedness by genetic similarity (MC2) gave strange results. For example, Ireland appeared well-connected to Germany, Belgium, France and The Netherlands (GS $>0.11$ ), better than the connectedness between Belgium and France or Belgium and Germany $(\mathrm{GS}<0.05)$. The reason was that some stallions, with high number of progenies had also one or two offspring in Ireland. In this case all progenies appeared in the numerator of GS, even with a huge disequilibrium between countries. That is why the percentage of progenies, provided by each country in the GS calculation was added to the results in Table 4. The GS criterion should be restricted to populations with rather equal number of progenies in each country. In dairy cattle, this might be more often the case as all bulls are tested on progenies but not in horse breeding. In our case, GS should be used only between Sweden and Germany or The Netherlands, between France and The Netherlands and between Germany and Belgium where the contribution of each country to GS were equal. Three of these comparisons gave very low GS $(1 \%$ to $3 \%)$, only one was medium: $18 \%$ between France and The Netherlands. We will not consider the GS as measurement of connectedness in the other cases in the remainder of discussion.

\subsection{Are MC3 and MC4 coherent measurements of connectedness?}

As MC2 revealed inadequacy, we have used two more elaborate criteria to evaluate the connectedness in two different aspects. MC3 focused on reliability of estimates of differences between countries, and MC4 focused on biases due to differences in level between countries.

Correlations between estimates of country effects (MC3) defined a group of four well-connected countries: 
Germany, Belgium, France and The Netherlands (correlations from 0.30 to 0.50 ). Lower results were obtained for Ireland and Sweden, and an intermediate position for Denmark but all correlations reached about 0.10 to 0.20 . The lower values for Sweden may be due to the rather small number of generally older stallions provided. These correlations can be compared to a balanced design with equal number of progenies in each country. A correlation of 0.40 corresponded in this balanced theoretical case to 13 progenies per stallion per country. So, present connectedness for the group of four is equivalent to a balanced design of progeny test with 11 to 19 progenies in each country, which in horse breeding is a convenient situation (30 offspring gave a reliability $(r)$ equal to 0.78 for the sire with $\left.h^{2}=0.20\right)$. The results from the method with the simulation of a systematic difference of genetic level (MC4) allowed us to have a good idea of the precision that we can hope to have in future comparisons of the EBV from different countries. According to genetic levels, there was one main exporting country: Germany which exported especially to Belgium, Denmark, The Netherlands and Sweden. Only two other countries were exporting countries: France and The Netherlands which exported to Belgium. There were four main importing countries: Belgium, Denmark, Ireland and Sweden. The Netherlands was at an intermediate level (genetic level 132.4). France and Germany were not importing countries (genetic level 103.4 and 110.5 respectively). Due to these exchanges, differences in genetic level varied from 33 (Denmark very close to Sweden) to 95.9 (France and Sweden). The percentage of differences in genetic level estimated varied from $24.9 \%$ (Belgium referent, Ireland pretender) to $63.9 \%$ (Germany referent, France pretender). In fact, the larger the difference is, the more estimable it becomes. So the differences were better estimated for Germany (mean 56\%) and France (mean $55 \%$ ) where the differences with other countries were higher (respectively mean 66 and 91 points) than for Belgium (mean 29\%) and Denmark (mean 34\%) where the differences were smaller (both mean 34 points). The fact that the countries were importing countries was the most influential: the more the country imports, the smaller is the simulated difference and so the difference is less well-estimated. These results are not in agreement with those found by Fouilloux et al., (2006) where the differences were better estimated when they were smaller. Also, the range of percentage of difference re-estimated was higher (mean 68\%) in Fouilloux et al. (2006) than in this study and so the relationship between percentage reestimated and simulated difference is perhaps different in a different range of situation. Another difference with the work of Fouilloux et al. (2006) is that we used relationship matrix between stallions. So that the difference between genetic levels of two stallions due to their different breeds (country of birth) was in fact related by the relationship matrix.

The methods MC3 and MC4 gave some different results. In both methods we found a group of wellconnected countries, however the composition of this group changed. Germany, France and The Netherlands were always in the well-connected group, but with $\mathrm{MC3}$, Belgium is in the well-connected group compared to Sweden when MC4 is used. With MC3 measurement, the lowest connected group is composed of Ireland and Sweden and with MC4 measurement, the lowest connected group is composed of Denmark, Ireland and Belgium. These differences may be explained by slightly different subsets used for each measure. In MC3, stallions with progenies' performances and own performances are used, whereas for MC4, only stallions with progenies' performances are used. This can lead to differences, especially in Belgium, where there are stallions without progenies' performances but with own performances, and these particular stallions are more numerous than in France where most of stallions have both own performances and progenies with performances. Another point to keep in mind is that the MC4 method rests on the correct identification of the breed for imported and exported stallions and the influence of different breeds in pedigree is not taken into account.

\subsection{Comparison of level of connectedness in horses' data with connectedness in official dairy cattle international genetic evaluation}

In international genetic evaluation of the dairy cattle by Interbull, connectedness between countries is only described by the number of common bulls between countries, i.e., bulls with multiple EBVs in different countries. Every evaluation, Interbull publishes the tables of number of bulls involved in international evaluation for each group of traits and ties by countries, so that it could be supposed that these numbers were sufficient for connectedness to allow international genetic evaluation. For the main trait, production trait, the most famous breed, Holstein, involved 25 countries with 149 to 24221 bulls. For the smallest breed, Guernsey, 6 countries are involved with 34 to 632 bulls. Common bulls in the first case vary from 0 to 1374 with often at least 200 common bulls for the most important countries. Our data is closer to the case of Brown Swiss (31 to 4162 bulls, 4 to 293 common bulls). However, stallions have a lower reliability of EBV than bulls because selection mainly occurs on own performances and number of potential progeny is ridiculous 
compared to bulls' reproduction. So that this raw number of common bulls is not very useful for connectedness in horses and relationship must be taken into account.

Other measurements of connectedness instead of number of common bulls (or half sibs' bulls) were used for dairy cattle populations. Most of them stayed on number of daughters of bulls and their distribution over countries and that is why we did not test them here because in horse breeding, connectedness was expected mostly from relationship between parents as stallions have few progeny compared to dairy bulls. Mark (1999) and then Jorjani (2000) proposed Statistical Connectedness (SC), with absolute and standardised values. These values were based on sum of differences between number of daughter of one bull compared to mean number of daughters within countries and within bulls. These measures were not easy to compare to GS because GS was based on balanced data over countries and SC on balanced data over bulls. Simultaneously, Weigel et al. (2000) computed number of common bulls, GS and two other measurements: mean relationship within and between countries, genetic constitutions (based on country of origin of grand parents) in Holstein data. They found good homogeneity between these measurements and insist on the use of mean relationship which can be related to $\mathrm{MC} 3$, correlation between countries effect (Kennedy and Trus, 1993). In these two publications, the level of GS was higher than the maximum available in our data (GS with balanced contributions only): 0.35 to 0.28 for the well-connected group in Holstein population against 0.18 between France and The Netherlands in this study. But they also found 25\% of GS (among 105 pairs) equal to 0 , to be compare to 0.01 to 0.05 obtained in the other well-balanced GS of our study. So our results were not so much different from dairy cattle situations in medium breeds.

\subsection{Are connectedness results sufficient for correct evaluation of genetic correlation between countries?}

Influence of connectedness on estimation of genetic correlation was mostly investigated in order to choose a subset of bulls in dairy cattle to calculate genetic correlation. The problem in dairy cattle was the choice of this subset as it was not possible to calculate genetic correlation over more than 20 countries and 20000 bulls per trait! With our data, there is no problem to calculate genetic correlation with 6137 stallions, 22324 ancestors and 7 countries.

However, strange genetic correlations were obtained in the weakly connected population of Ayrshire by Klei and Lawlor (2001) but these populations involved less than 51 bulls in common (mean 6) so largely smaller than in our data. Jorjani et al. (2005) used a simulation study to measure the level of connectedness suitable for genetic correlation estimation. Conclusions were that a sub setting strategy of bulls is suitable and should be done on a value per sire based on sum of differences among countries between progeny tested in the country and mean progeny tested for the bull. The measure ranked bulls according to the homogeneity of their progeny among countries and number of countries where the sire has an EBV but did not take into account the absolute number of progeny. Thresholds retained suggested that for 6 countries involved, a bull with homogeneous progeny in only two countries is available. Even if this measure give a more particle management of data to compute genetic correlation than GS, it do not seem well-adapted to horse breeding because own performance of stallions and relationship matrix was not taken into account. Mark et al. (2005b), showed strong differences between genetic correlations when number of common bulls is lower than 20 in an Ayshir population but based on common bulls. But the data was very much unfavourable than the present study with only 0 to 61 common bulls and 9 countries (Mark et al., 2005a). In our study, 13 pairs of countries over 21 had more than 20 common stallions and all but one when excluding Sweden.

\subsection{Comparison with other measurement of connectedness in horse breeding}

The first ones who implemented international genetic evaluation in horses were Arnason and Sigurdsson (1997) for Icelandic Toelter horses between Iceland and Sweden. The connectedness between countries was then estimated (Arnason and Ricard 2001, Arnason and Sigurdsson 2004, Arnasson et al., 2006) from variance-covariance of the country effects, translated here for easier comparison with our results in correlations. The later results were for the year 2005 for 11 countries, 1319 horses and 8198 animals in pedigree. The highest correlation between country effect was 0.62 (Iceland and Germany) and the lowest 0.04 (Finland and Great Britain) with mean 0.21 and a well-connected group involving Iceland, Sweden, Denmark, Norway and Germany with correlations higher than 0.30. So connectedness in our data was of same magnitude with lower maximum but with the same order for the well-connected group (Germany, Belgium, France, The Netherlands).

On sport horses, the results of the first Interstallion Pilot project has just been published (Thorén et al., in press). Connectedness was measured on young horse test results in four countries (and two stud books in Germany) 
based on 2457 stallions with 5868 pedigree horses. A lower number of stallions were provided to our study from Sweden, higher from The Netherlands and similar from Germany and Denmark. Belgium, France and Ireland were not involved in the first project. Information requested in our study referred to a shorter period of time than in Thorén et al. (in press), so stallions were a younger sample: $43 \%$ of stallions were born after 1985 in Thorén et al. (in press) compared to $54 \%$ in the present study. The larger time frame allowed Thorén et al. (in press) to study evolution of connectedness over time but that was not possible here. Reliability of EBV of stallions provided from Germany, Denmark and The Netherlands was similar between the two studies but higher for Sweden in the present study. The number of common stallions was largely lower between Sweden and all other countries and higher between The Netherlands and Germany or Denmark. The data in the first pilot project presented the same problem than in our project about balanced design for GS so that only 4 GS pairs were available. These GS were higher (0.07 to 0.18$)$ especially between Sweden and Denmark or Hanoverian and Holstein German stud book. Correlations between estimates of country effect were surprisingly low: 0.01 to 0.04 with a maximum 0.04 between Hanoverian and Holstein. This could not be explained by lack of data because the number of stallions and progeny was high. The only explanation could be the very unbalanced progeny in the different countries/stud books by sires even with balanced data at the country level. Effectively, a sire with unbalanced data among countries is weighed at the country level by another sire with complementary unbalanced data and this could not be seen with GS but with correlation between country effects. Thorén et al. (in press) concluded that the genetic connectedness was good enough between the five countries/stud book involved. By comparison, with higher correlations, we can give the same conclusion.

\section{Conclusion}

The various measures of connectedness indicate that there are enough genetic links to allow estimates of genetic correlations among the populations in question according to comparison with literature in dairy cattle or horse breeding. However, the differences in sampling data from the participating countries may seriously affect the estimates obtained. For more accurate estimates, stallions sample used should be more similar: with same time period of birth of the stallions and reliability of their EBVs. More, horses with international career must be known and this special kind of data studied. There is no unique measurement of connectedness and each measurement reveals different default of the pattern used to compare countries. The wellconnected group was found to be France, The Netherlands and Germany and optionally Belgium or Sweden. In either situation, these first results are encouraging and allow the calculation of genetic correlations, the next stage of the pilot project of Interstallion. Besides, connectedness is expected to increase in the future due to the increasing exchange of genetic material.

\section{Acknowledgements}

We thank Erwin Koenen for his help and valuable suggestions for this work. We also thank Les Haras Nationaux and l'Association Nationale du Selle Français (France) for the financing support of this project.

We thank also all the 22 breeding organisations for their participation (for the complete list see Table 1).

\section{References}

Arnason, T., Ricard, A., 2001. Method for international genetic evaluation of sport horses. 52nd Annual Meeting of the EAAP. EAAP Book of Abstracts, Budapest, Hungary, p. 347.

Arnason, T., Sigurdsson, A., 1997. Genetic analysis of performance test traits in Icelandic toelter horses in Iceland and Sweden. 48th Annual Meeting of the EAAP. EAAP Book of Abstracts, Vienna, Austria, p. 377.

Arnason, T., Sigurdsson, A., 2004. International genetic evaluation of the Icelandic horse. 55th Annual Meeting of the EAAP. EAAP Book of Abstracts. Bled, Slovenia, p. 327.

Arnason, T., Sigurdsson, A., Lorange, J.B., 2006. Global genetic evaluations of the Icelandic horse and genetic connectedness between countries. Proc. 8th World Cong. Gen. Appl. to Livest. Prod. WCGALP Book of Abstracts, Belo Horizonte, Minas Gerais, Brazil, p. 229.

Bruns, E., Ricard, A., Koenen, E.P.C., 2004. Interstallion - on the way to an international genetic evaluation of sport horses. 55th Annual Meeting of the EAAP. EAAP Book of Abstracts. Bled, Slovenia, p. 326.

Fouilloux, M.-N., Minery, S., Mattalia, S., Laloë, D., 2006. Assessment of Connectedness in the International Genetic Evaluation of Simmental and Montbéliard Breeds. Interbull Meeting, Interbull Bulletin, vol. n³5. Kuopio, Finland, pp. 129-135.

Jorjani, H., 2000. Well-Connected, Informative Sub-Set of Data. Interbull Meeting. Interbull Bulletin, vol. $\mathrm{n}^{\circ} 25$. Bled, Slovenia, pp. 51-55.

Jorjani, H., Emanuelson, U., Fikse, W.F., 2005. Data subsetting strategies for estimation of across-country genetic correlations. J. Dairy Sci. 88, 1214-1224.

Kennedy, B.W., Trus, D., 1993. Considerations on genetic connectedness between management units under an animal model. J. Anim. Sci. 71, 2341-2352.

Klei, B., Lawlor, T., 2001. Mace for conformation Ayrshires. Interbull Meeting. Interbull Bulletin n²7, Budapest, Hungary, pp. 51-55.

Koenen, E.P.C., Aldridge, L.I., 2002. Testing and genetic evaluation of sport horses in an international perspective. Proc. 7th World Cong. Gen. Appl. to Livest. Prod. WCGALP Book of Abstract, Montpellier, France, p. 367. 
Koenen, E.P.C., Aldridge, L.I., Philipsson, J., 2004. An overview of breeding objectives for warmblood sport horses. Livest. Prod. Sci. $88,77-84$.

Mark, T., 1999. International Genetic Evaluation of Dairy Sires for Clinical Mastitis and Somatic Cell Count. Royal Veterinary \& Agricultural University of Copenhagen, Copenhagen, p. 111.

Mark, T., Madsen, P., Jensen, J., Fikse, W.F., 2005a. Difficulties in estimating across-country genetic correlations for weakly linked bull populations. J. Dairy Sci. 88, 3303-3305.

Mark, T., Madsen, P., Jensen, J., Fikse, W.F., 2005b. Prior (co) variances can improve multiple-trait across-country evaluations of weakly linked bull populations. J. Dairy Sci. 88, 3290-3302.

Philipsson, J., 1987. Standards and procedures for international genetic evaluations of dairy cattle. J. Dairy Sci. 70, 418-424.

Rekaya, R., Weigel, K.A., Gianola, D., 2003. Bayesian estimation of parameters of a structural model for genetic covariances between milk yield in five regions of the United States. J. Dairy Sci. 86, 1837-1844.
Thorén Hellsten, E., Jorjani, H., Philipsson, J., in press. Connectedness among five European sport horse populations. Livest. Sci. Available online 30 January 2008.

Thoren Hellsten, E., Viklund, A., Koenen, E.P.C., Ricard, A., Bruns, E., Philipsson, J., 2006. Review of genetic parameters estimated at stallion and young horse performance tests and their correlations with later results in dressage and show-jumping competition. Livest. Sci. 103, 1-12.

Weigel, K.A., Rekaya, R., Fikse, W.F., Zwald, N., Gianola, D., 2000. Data Structure and Connectedness Issues in International Dairy Sire Evaluations. Interbull Meeting. Interbull Bulletin, vol. $\mathrm{n}^{\circ} 25$. Bled, Slovenia, pp. 26-30.

\section{Internet References}

UELN www.ueln.com Accessed 2000

WBFSH website with an INTERSTALLION part www.wbfsh.org Accessed 2005-05-19 